\title{
Novel and known genetic variants for male breast cancer risk at 8q24.21, 9p21.3, 11q13.3 and 14q24.1: Results from a multicenter study in Italy
}

\author{
Valentina Silvestri $^{\mathrm{a}}$, Piera Rizzolo ${ }^{\mathrm{a}}$, Marco Scarnò ${ }^{\mathrm{b}}$, Giovanni Chillemi ${ }^{\mathrm{b}}$, \\ Anna Sara Navazio ${ }^{a}$, Virginia Valentini ${ }^{a}$, Veronica Zelli ${ }^{a}$, Ines Zanna ${ }^{c}$, \\ Calogero Saieva ${ }^{\mathrm{c}}$, Giovanna Masala ${ }^{\mathrm{c}}$, Simonetta Bianchi ${ }^{\mathrm{d}}$, Siranoush Manoukian ${ }^{\mathrm{e}}$, \\ Monica Barile $^{\mathrm{f}}$, Valeria Pensotti ${ }^{\mathrm{g}}$, Paolo Peterlongo ${ }^{\mathrm{h}}$, Liliana Varesco ${ }^{\mathrm{i}}$, \\ Stefania Tommasi ${ }^{j}$, Antonio Russo ${ }^{\mathrm{k}}$, Giuseppe Giannini ${ }^{\mathrm{a}}$, Laura Cortesi ${ }^{1}$,
} Alessandra Viel ${ }^{\mathrm{m}}$, Marco Montagna ${ }^{\mathrm{n}}$, Paolo Radice ${ }^{\circ}$, Domenico Palli ${ }^{\mathrm{c}}$, Laura Ottini ${ }^{\mathrm{a}, *}$

${ }^{a}$ Department of Molecular Medicine, Sapienza University of Rome, Italy

${ }^{\mathrm{b}}$ CINECA (Inter University Consortium for Super Computing), Rome, Italy

${ }^{\mathrm{c}}$ Molecular and Nutritional Epidemiology Unit, Cancer Research and Prevention Institute (ISPO), Florence, Italy

${ }^{\mathrm{d}}$ Division of Pathological Anatomy, Department of Medical and Surgical Critical Care, University of Florence, Florence, Italy

${ }^{\mathrm{e}}$ Unit of Medical Genetics, Department of Preventive and Predictive Medicine, Fondazione IRCCS, Istituto Nazionale dei Tumori, Milan, Italy

${ }^{\mathrm{f}}$ Division of Cancer Prevention and Genetics, Istituto Europeo di Oncologia, Milan, Italy

${ }^{\mathrm{g}}$ Fondazione Istituto FIRC di Oncologia Molecolare (IFOM) and Cogentech Cancer Genetic Test Laboratory, Milan, Italy

${ }^{\mathrm{h}}$ Fondazione Istituto FIRC di Oncologia Molecolare (IFOM), Milan, Italy

${ }^{\text {i } U n i t ~ o f ~ H e r e d i t a r y ~ C a n c e r s, ~ I R C C S ~ A O U ~ S a n ~ M a r t i n o ~-~ I S T, ~ G e n o a, ~ I t a l y ~}$

${ }^{\mathrm{j}}$ Molecular Genetics Laboratory, Istituto Tumori "Giovanni Paolo II", Bari, Italy

${ }^{\mathrm{k}}$ Section of Medical Oncology, Department of Surgical and Oncological Sciences, University of Palermo, Italy

${ }^{1}$ Department of Oncology and Haematology, University of Modena and Reggio Emilia, Modena, Italy

${ }^{\mathrm{m}}$ Unit of Experimental Oncology 1, CRO Aviano, National Cancer Institute, Aviano (PN), Italy

${ }^{\mathrm{n}}$ Immunology and Molecular Oncology Unit, Veneto Institute of Oncology IOV - IRCCS, Padua, Italy

${ }^{\circ}$ Unit of Molecular Bases of Genetic Risk and Genetic Testing, Department of Preventive and Predictive Medicine, Fondazione IRCCS Istituto Nazionale Tumori (INT), Milan, Italy

Received 15 April 2015; accepted 16 July 2015

Available online 3 August 2015

\section{KEYWORDS}

Male breast cancer

BRCA1/2

\begin{abstract}
Increasing evidence indicates that common genetic variants may contribute to the heritable risk of breast cancer (BC). In this study, we investigated whether single nucleotide polymorphisms (SNPs), within the 8q24.21 multi-cancer susceptibility region and within
\end{abstract}

\footnotetext{
* Corresponding author at: Department of Molecular Medicine "Sapienza" University of Rome Viale Regina Elena, 324 00161, Rome, Italy. Tel.: +3906 49973009; fax: +3906 4464129.

E-mail address: laura.ottini@uniroma1.it (L. Ottini).
} 


\section{$8 \mathrm{q} 24.21$}

Low-penetrance BC

alleles

SNPs

Clinical-pathologic

characteristics
BC-associated loci widespread in the genome, may influence the risk of BC in men, and whether they may be associated with specific clinical-pathologic characteristics of male $\mathrm{BC}$ (MBC).

In the frame of the ongoing Italian Multicenter Study on $\mathrm{MBC}$, we performed a case-control study on $386 \mathrm{MBC}$ cases, including $50 \mathrm{BRCA1/2}$ mutation carriers, and 1105 healthy male controls, including 197 unaffected BRCA1/2 mutation carriers. All 1491 subjects were genotyped by Sequenom iPLEX technology for a total of 29 susceptibility SNPs.

By logistic regression models, we found a significant association with MBC risk for five SNPs: rs1562430 $(p=0.002)$ and $\operatorname{rs} 445114(p=0.026)$ both within the 8q24.21 region; rs 1011970/9p21.3 $(p=0.011), \quad$ rs614367/11q13.3 $\quad(p=0.016) \quad$ and $\quad$ rs $1314913 / 14 \mathrm{q} 24.1$ $(p<0.0001)$.

Differences in the distribution of rs614367/11q13.3 genotypes according to oestrogen receptor (ER) status $(p=0.006)$, and of rs1011970/9p21.3 genotypes according to human epidermal growth factor receptor 2 (HER2) status $(p=0.002)$ emerged. Association of rs 1011970/9p21.3 risk genotype with HER2+ MBC was confirmed by a multivariate analysis. rs1314913/14q24.1 was associated with increased MBC risk in analyses restricted to male $B R C A 1 / 2$ mutation carriers $(p=0.041)$.

In conclusion, we provided the first evidence that the $8 \mathrm{q} 24.21$ region is associated with MBC risk. Furthermore, we showed that the SNPs rs1562430/8q24.21 and rs1314913/14q24.1 strongly influence BC risk in men and suggested that the SNP rs1314913/14q24.1 may act as a risk modifier locus in male $B R C A 1 / 2$ mutation carriers.

(C) 2015 Elsevier Ltd. All rights reserved.

\section{Introduction}

Male breast cancer (MBC) is a rare disease representing less than $1 \%$ of all breast cancers (BCs) and less than $1 \%$ of all cancers in men [1]. About $20 \%$ of $\mathrm{MBC}$ patients show positive family history of $\mathrm{BC}$ and about $20 \%$ develop a second non-breast tumour, in particular prostate and colon cancer [2]. These observations point to a relevant genetic component in $\mathrm{MBC}$ predisposition.

Mutations in high-penetrance $\mathrm{BC}$ genes, $B R C A 1$ and, more frequently, $B R C A 2$, and in moderate-penetrance genes, such as $C H E K 2$ and $P A L B 2$, have a relevant role in MBC susceptibility [3]. However, only about $10-15 \%$ of all MBCs are accounted for by mutations in these genes, thus, much of the genetic contribution to MBC risk still remains to be elucidated.

Growing evidence indicates that the genetic susceptibility to cancer can be attributed to the combined effects of low-penetrance susceptibility single nucleotide polymorphisms (SNPs) [4,5]. A large number of SNPs, identified through Genome Wide Association Studies (GWAS) or candidate gene approach, have been associated with many types of cancer, including BC $[6,7]$.

Multiple GWAS have identified SNPs within 8q24.21 region that are linked to susceptibility for different types of cancer [8-15]. Five distinct 8q24.21 sub-regions have emerged, displaying patterns of association that appear to be specific for breast, colorectal and prostate cancer $[16,17]$. In particular, three regions were associated with prostate cancer only, one with prostate and colorectal cancer and one with prostate and breast cancer [18]. The $8 \mathrm{q} 24.21$ susceptibility region has been described as a gene-desert because of the lacking of annotated protein-coding genes [19]. However, the c-MYC oncogene, which is located $300 \mathrm{~kb}$ telomeric, seems the most likely candidate to be functionally linked to the susceptibility conferred by the 8q24.21 SNPs and there is evidence that its expression may be affected by SNPs within 8q24.21 region [17,20].

To date, a large number of studies have been performed to investigate low-penetrance genetic susceptibility in female BC (FBC), and susceptibility alleles have been reported in about 70 loci widespread in the genome [21]. By contrast, only a few studies addressed the role of low-penetrance alleles in MBC susceptibility [22-24].

Two SNPs, rs1314913 in RAD51B gene and rs3803662 near TOX3 gene, were found to be associated with MBC risk by GWAS. In particular, rs1314913 was found specifically associated with increased BC risk in men, whereas rs3803662 was found associated with increased BC risk also in women [23]. Furthermore, by gene candidate approach ESRI locus was found to be associated with $\mathrm{BC}$ risk in men, and, in particular, with increased risk in oestrogen receptor (ER) negative $\mathrm{MBC}$ cases and in male BRCA1/2 mutation carriers [22,24].

Based on the observation that MBC cases may frequently develop additional non-breast tumours, in this study we explored the possibility that the 8q24.21 multi-cancer susceptibility region may have a role in MBC risk. In addition, we aimed to evaluate whether other common low-penetrance susceptibility alleles, recently identified and associated with $\mathrm{BC}$ risk in women $[15,25,26]$, may also influence BC risk in men. Finally, we explored possible associations between SNPs and clinical-pathologic characteristics of $\mathrm{MBC}$, in order to provide further insight into the biological basis of $\mathrm{BC}$ 
in men, and eventually improve both the identification of men at risk to develop this rare disease and the personalised clinical management of MBC patients.

\section{Patients and methods}

\subsection{Study population}

The study was performed comparing a series of 386 MBC cases, including $50 \mathrm{BRCA1} / 2$ mutation carriers, and 908 healthy male controls. An additional control series of 197 healthy male BRCA1/2 mutation carriers was collected and analysed.

Cases, together with their clinical-pathologic characteristics, were recruited in the frame of the ongoing Italian Multicenter Study on MBC, as previously described $[24,27]$. Overall, mean age at first BC diagnosis was 61.3 years (SD 11.8); 152 cases (39.4\%) reported first-degree family history of breast and/or ovarian cancer and 61 cases $(15.8 \%)$ had a personal history of other cancers (16 prostate, 9 colorectal and 6 bladder cancers). Regarding $B R C A 1 / 2$ mutation status, 2 cases $(0.6 \%)$ carried $B R C A 1$ and $48(12.4 \%) B R C A 2$ mutations. The majority of male breast tumours were invasive ductal carcinomas $(85.8 \%), \quad$ ER $+(92.7 \%)$, progesterone receptor $(\mathrm{PR})+(86.3 \%)$ and HER $2-(75.2 \%)$.

Controls were obtained from individuals enrolled under research or clinical protocols and from blood donors. All controls were residing in the same areas of cases.

The study was approved by Local Ethics Committee ("Sapienza" University of Rome, Prot. 264/12).

\subsection{Blood collection and DNA extraction/genotyping}

From each of the 1491 participants, blood or DNA samples were obtained. DNA was extracted and quantified as already described [24]. MBC cases and controls were genotyped by using MALDI-TOF spectrophotometric mass determination of allele specific primer extension products with Sequenom's MassARRAY platform and iPLEX technology (Sequenom, San Diego, USA). Optimal amplification and extension primers for use in a multiplex format were designed. A total of 19 susceptibility SNPs within 8q24.21 region and 10 candidate BC susceptibility SNPs were genotyped (Supplementary Table 1). MALDI-TOF mass analysis was performed on a MassARRAY Compact Analyzer. Data were analysed with Sequenom's MassARRAY Typer software. Genotyping calls were viewed in call cluster plots, and peak intensities were reviewed in each respective sample spectrum.

\subsection{Statistical analyses}

The genotype frequencies for each individual DNA polymorphism were evaluated in both series of cases and controls, and deviations from Hardy-Weinberg equilibrium in controls were assessed by a Chi-square test with one degree of freedom. Considering a minor allele frequency of $13 \%$ (lower value in our control's series) and a dominant model, with a case-control ratio of 1:2.3 (386 cases and 908 controls), we could identify an odds ratio (OR) of 1.53 with a power of $90 \%$ and $\alpha=0.05$. Chi-square test was used to evaluate the potential association between genotypes of the 29 SNPs and the presence of the disease. Linear logistic regression models, adjusted for enrolment centre and age of participants, were performed to assess the association between each SNP found potentially associated with the disease and overall MBC risk by ORs and their $95 \%$ confidence intervals (CIs). For each SNP, a specific model was used to evaluate separately the effect of the heterozygous genotype and of the rare homozygous genotype. In each model, the common homozygote genotype (in the control population) was considered as the reference category. We also evaluated MBC risk by multiplicative co-dominant model, as estimate of the per-allele effect.

An additional step-wise analysis applied to a linear logistic regression in which all the SNPs appeared as main effects was performed.

Chi-square test and logistic regression models were also performed in a case-case analysis in order to evaluate the difference of specific parameters between different groups of cases and the potential associations between genetic susceptibility and specific $\mathrm{MBC}$ clinical-pathologic characteristics. A $p$-value $<0.05$ was considered statistically significant. All the analyses were performed using SAS (SAS/STAT version 9.1) statistical program.

\section{Results}

The whole series of 1491 subjects was genotyped at 29 SNPs, including 19 SNPs in 8q24.21 region and 10 candidate BC susceptibility SNPs across the genome. Genotype distribution was consistent with HardyWeinberg equilibrium among controls for all SNPs analysed.

A statistically significant difference in the distribution of genotypes in $386 \mathrm{MBC}$ cases and 908 healthy male controls (Supplementary Table 2) emerged for five SNPs: $\operatorname{rs} 1562430(p<0.0001)$ and $\operatorname{rs} 445114(p=0.01)$ both within the breast/prostate cancer sub-region in 8q24.21, and rs1011970/9p21.3 $(p=0.009)$, rs614367/ $11 \mathrm{q} 13.3(p=0.008)$ and rs1314913/14q24.1 $(p<0.0001)$.

As shown in Table 1, statistically significant associations between MBC risk and these five SNPs emerged by linear logistic regression models. Compared with the reference genotype, the following ORs for the rare homozygous were found for the 8q24.21 SNPs: rs1562430 $\mathrm{OR}=0.52 \quad(95 \% \quad \mathrm{CI}: \quad 0.34-0.79 ; \quad p=0.002) \quad$ and $\mathrm{rs} 445114 \mathrm{OR}=1.57(95 \% \mathrm{CI}: 1.05-2.34 ; p=0.026)$. Of 
Table 1

Distribution of 386 cases and 908 controls according to genotype frequencies and male breast cancer risk estimates for selected susceptibility SNPs.

\begin{tabular}{|c|c|c|c|c|c|c|c|}
\hline SNP & Chromosome & Gene & Genotype & Cases N $(\%)$ & Controls N $(\%)$ & $\mathrm{OR}^{\mathrm{a}}(95 \% \mathrm{CI})$ & $p$-Value ${ }^{a}$ \\
\hline rs $1562430^{\mathrm{b}}$ & $8 \mathrm{q} 24.21$ & & $\begin{array}{l}\text { TT } \\
\text { TC } \\
\text { CC } \\
\text { Co-dominant }\end{array}$ & $\begin{array}{l}172(44.6) \\
173(44.8) \\
41(10.6)\end{array}$ & $\begin{array}{l}319(35.1) \\
427(47) \\
162(17.9)\end{array}$ & $\begin{array}{l}1 \\
0.80(0.60-1.06) \\
\mathbf{0 . 5 2}(\mathbf{0 . 3 4 - 0 . 7 9 )} \\
\mathbf{0 . 7 2}(\mathbf{0 . 5 9 - 0 . 8 7 )}\end{array}$ & $\begin{array}{l}0.11 \\
0.002 \\
0.0006\end{array}$ \\
\hline rs445114 & $8 \mathrm{q} 24.21$ & & $\begin{array}{l}\text { TT } \\
\text { TC } \\
\text { CC } \\
\text { Co-dominant }\end{array}$ & $\begin{array}{l}141(36.5) \\
178(46.1) \\
67(17.4)\end{array}$ & $\begin{array}{l}372(41) \\
433(47.7) \\
102(11.3)\end{array}$ & $\begin{array}{l}1 \\
1.12(0.84-1.48) \\
\mathbf{1 . 5 7}(\mathbf{1 . 0 5}-\mathbf{2 . 3 4}) \\
\mathbf{1 . 2 5}(\mathbf{1 . 0 3 - 1 . 5 0 )}\end{array}$ & $\begin{array}{l}0.43 \\
\mathbf{0 . 0 2 6} \\
\mathbf{0 . 0 2 1}\end{array}$ \\
\hline rs 1011970 & $9 \mathrm{p} 21.3$ & CDKN2A/CDKN2B & $\begin{array}{l}\text { GG } \\
\text { GT } \\
\text { TT } \\
\text { Co-dominant }\end{array}$ & $\begin{array}{l}264(68.4) \\
101(26.2) \\
21(5.4)\end{array}$ & $\begin{array}{l}655(72.1) \\
233(25.7) \\
20(2.2)\end{array}$ & $\begin{array}{l}1 \\
1.05(0.78-1.41) \\
\mathbf{2 . 3 8}(\mathbf{1 . 2 2}-\mathbf{4 . 6 4 )} \\
1.23(0.98-1.55)\end{array}$ & $\begin{array}{l}0.73 \\
\mathbf{0 . 0 1 1} \\
0.09\end{array}$ \\
\hline rs614367 & $11 \mathrm{q} 13.3$ & CCND1 & $\begin{array}{l}\text { CC } \\
\text { CT } \\
\text { TT } \\
\text { Co-dominant }\end{array}$ & $\begin{array}{l}266(69.3) \\
102(26.6) \\
16(4.1)\end{array}$ & $\begin{array}{l}678(75.1) \\
209(23.2) \\
15(1.7)\end{array}$ & $\begin{array}{l}1 \\
1.22(0.91-1.64) \\
\mathbf{2 . 5 7}(\mathbf{1 . 1 9 - 5 . 5 4 )} \\
\mathbf{1 . 2 9}(\mathbf{1 . 0 1 - 1 . 6 5 )}\end{array}$ & $\begin{array}{l}0.19 \\
0.016 \\
0.044\end{array}$ \\
\hline rs 1314913 & $14 q 24.1$ & RAD51B & $\begin{array}{l}\text { GG } \\
\text { GA } \\
\text { AA } \\
\text { Co-dominant }\end{array}$ & $\begin{array}{l}188(48.7) \\
161(41.7) \\
37(9.6)\end{array}$ & $\begin{array}{l}583(64.2) \\
286(31.5) \\
39(4.3)\end{array}$ & $\begin{array}{l}1 \\
1.83(1.39-2.41) \\
3.10(1.84-5.22) \\
1.83(1.48-2.24)\end{array}$ & $\begin{array}{l}<0.0001 \\
<0.0001 \\
<0.0001\end{array}$ \\
\hline
\end{tabular}

Abbreviations: SNP, Single Nucleotide Polymorphism; OR, Odds Ratio; CI, Confidence Interval.

a ORs and p-values from logistic regression models adjusted for centre of enrolment and age of participants. Statistically significant results in bold text.

${ }^{\mathrm{b}}$ For this SNP, major allele $\mathrm{T}$ is the risk allele, as previously reported [15].

these two SNPs, rs445114 showed no independent association with MBC risk after adjustment for rs1562430 (data not shown). The following ORs for the rare homozygous were found for the other candidate BC susceptibility SNPs: $\quad$ rs $1011970 / 9 \mathrm{p} 21.3$ OR $=2.38 \quad(95 \%$ CI: $1.22-4.64 ; \quad p=0.011), \quad \mathrm{rs} 614367 / 11 \mathrm{q} 13.3 \quad \mathrm{OR}=2.57$ (95\% CI: $1.19-5.54 ; p=0.016$ ), and rs1314913/14q24.1 $\mathrm{OR}=3.10$ (95\% CI: $1.84-5.22 ; p<0.0001)$.

By using a stepwise approach in which all 29 SNPs were included, rs1562430/8q24.21 (OR for rare homozygous $=0.54, \quad 95 \% \quad \mathrm{CI}: \quad 0.35-0.83 ; \quad p=0.0043)$ and rs1314913/14q24.1 (OR for rare homozygous $=3.00$, 95\% CI: $1.78-5.07 ; p<0.0001)$ emerged as the SNPs more strongly associated with MBC risk.

We then restricted the analysis to male $B R C A 1 / 2$ mutation carriers, by comparing 50 BRCAl/2 mutation positive MBC cases with a control group of 197 unaffected BRCA1/2 carriers (Supplementary Table 3). Differences in the distribution of genotypes between affected and unaffected $B R C A 1 / 2$ carriers emerged for rs1314913/14q24.1 ( $p=0.017)$. A statistically significant association between rs1314913/14q24.1 risk genotype and increased $\mathrm{MBC}$ risk in BRCA1/2 carriers emerged $(\mathrm{OR}$ for rare homozygous $=3.22 ; 95 \%$ CI $1.02-10.17$; $p=0.046$. OR for co-dominant model $=1.69 ; 95 \% \mathrm{CI}$ $1.02-2.78 ; p=0.041)$.

We further analysed the distribution of the five SNPs associated with overall $\mathrm{MBC}$ risk in the series of $\mathrm{MBC}$ cases, according to clinical-pathologic features including hormone receptors (ER/PR) and HER2 status (Table 2).
The frequency of the rs1011970/9p21.3 risk genotype tended to be higher in HER2+ cases $(p=0.002)$, whereas the frequency of rs614367/11q13.3 risk genotype tended to be higher in ER+ cases $(p=0.006)$. In a case-case multivariate analysis adjusted for centre of enrolment and age of patients, a statistically significant association between rs1011970/9p21.3 risk genotype and HER $2+$ status emerged $(\mathrm{OR}=3.30,95 \% \mathrm{CI}$ : $1.09-9.98 ; p=0.034)$.

We also evaluated the distribution of the five SNP genotypes in the MBC series according to selected tumour characteristics, such as tumour grade, stage and nodal involvement, and no significant differences in genotype distribution emerged (data not shown).

\section{Discussion}

In this study, we investigated 29 cancer-associated SNPs for their associations with BC risk in men.

Five out of the 29 SNPs analysed were found associated with MBC risk: rs1562430 and rs445114, both within the 8q24.21 region, and rs1011970/9p21.3, rs614367/11q13.3 and rs1314913/14q24.1. By stepwise analysis, rs1562430/8q24.21 and rs1314913/14q24.1 showed the strongest association with $\mathrm{MBC}$ risk.

Our results provide the first evidence that the 8q24.21 region is associated with $\mathrm{MBC}$ risk. The $8 \mathrm{q} 24.21$ region harbours five distinct susceptibility sub-regions including three associated with prostate cancer, one with prostate and colorectal cancer and one with prostate and 
Table 2

Distribution of the five SNPs associated with overall (MBC) risk in the cases series according to ER, PR and HER2 status, and p values of the association with specific MBC subtypes.

\begin{tabular}{|c|c|c|c|c|c|c|c|c|}
\hline \multirow[t]{2}{*}{ SNP } & \multirow[t]{2}{*}{ Chromosome/Gene } & & \multicolumn{2}{|l|}{ ER } & \multicolumn{2}{|l|}{ PR } & \multicolumn{2}{|l|}{ HER2 } \\
\hline & & & $\begin{array}{l}- \\
(n: 22) \\
n(\%) \\
\end{array}$ & $\begin{array}{l}+ \\
(n: 279) \\
n(\%)\end{array}$ & $\begin{array}{l}- \\
(n: 41) \\
n(\%)\end{array}$ & $\begin{array}{l}+ \\
(n: 259) \\
n(\%)\end{array}$ & $\begin{array}{l}- \\
(n: 170) \\
n(\%)\end{array}$ & $\begin{array}{l}+ \\
(n: 56) \\
n(\%) \\
\end{array}$ \\
\hline rs1562430 & $8 \mathrm{q} 24.21$ & $\begin{array}{l}\text { TT } \\
\text { TC } \\
\text { CC } \\
p \text {-Value }\end{array}$ & $\begin{array}{l}8(36.4) \\
10(45.4) \\
4(18.2) \\
0.388\end{array}$ & $\begin{array}{l}123(44.1) \\
130(46.6) \\
26(9.3)\end{array}$ & $\begin{array}{l}16(39.0) \\
17(41.5) \\
8(19.5) \\
0.092\end{array}$ & $\begin{array}{l}114(44.0) \\
123(47.5) \\
22(8.5)\end{array}$ & $\begin{array}{l}74(43.5) \\
75(44.1) \\
21(12.4) \\
0.559\end{array}$ & $\begin{array}{l}26(46.4) \\
26(46.4) \\
4(7.2)\end{array}$ \\
\hline rs445114 & $8 \mathrm{q} 24.21$ & $\begin{array}{l}\text { TT } \\
\text { TC } \\
\text { CC } \\
p \text {-Value }\end{array}$ & $\begin{array}{l}10(45.5) \\
11(50.0) \\
1(4.5) \\
0.248\end{array}$ & $\begin{array}{l}101(36.2) \\
127(45.5) \\
51(18.3)\end{array}$ & $\begin{array}{l}14(34.2) \\
24(58.5) \\
3(7.3) \\
0.114\end{array}$ & $\begin{array}{l}97(37.5) \\
114(44.0) \\
48(18.5)\end{array}$ & $\begin{array}{l}66(38.8) \\
76(44.7) \\
28(16.5) \\
0.913\end{array}$ & $\begin{array}{l}20(35.7) \\
26(46.4) \\
10(17.9)\end{array}$ \\
\hline rs1011970 & $9 \mathrm{p} 21.3 / C D K N 2 A / B$ & $\begin{array}{l}\mathrm{GG} \\
\mathrm{GT} \\
\mathrm{TT} \\
p \text {-Value }\end{array}$ & $\begin{array}{l}17(77.3) \\
4(18.2) \\
1(4.5) \\
0.683\end{array}$ & $\begin{array}{l}191(68.5) \\
73(26.2) \\
15(5.3)\end{array}$ & $\begin{array}{l}31(75.6) \\
8(19.5) \\
2(4.9) \\
0.6\end{array}$ & $\begin{array}{l}176(68.0) \\
69(26.6) \\
14(5.4)\end{array}$ & $\begin{array}{l}110(64.7) \\
53(31.2) \\
7(4.1) \\
\mathbf{0 . 0 0 2}\end{array}$ & $\begin{array}{l}41(73.2) \\
7(12.5) \\
8(14.3)\end{array}$ \\
\hline rs614367 & $11 \mathrm{q} 13.3 / C C N D 1$ & $\begin{array}{l}\text { CC } \\
\text { CT } \\
\text { TT } \\
\text { p-Value }\end{array}$ & $\begin{array}{l}9(42.9) \\
12(57.1) \\
0(0.0) \\
\mathbf{0 . 0 0 6}\end{array}$ & $\begin{array}{l}195(70.1) \\
70(25.2) \\
13(4.7)\end{array}$ & $\begin{array}{l}25(62.5) \\
14(35.0) \\
1(2.5) \\
0.467\end{array}$ & $\begin{array}{l}178(69.0) \\
68(26.4) \\
12(4.6)\end{array}$ & $\begin{array}{l}112(66.3) \\
50(29.6) \\
7(4.1) \\
0.81\end{array}$ & $\begin{array}{l}34(61.8) \\
18(32.7) \\
3(5.5)\end{array}$ \\
\hline rs1314913 & $14 \mathrm{q} 24.1 / R A D 51 B$ & $\begin{array}{l}\text { GG } \\
\text { GA } \\
\text { AA } \\
p \text {-Value }\end{array}$ & $\begin{array}{l}14(63.6) \\
5(22.7) \\
3(13.7) \\
0.222\end{array}$ & $\begin{array}{l}134(48.0) \\
116(41.6) \\
29(10.4)\end{array}$ & $\begin{array}{l}23(56.1) \\
11(26.8) \\
7(17.1) \\
0.115\end{array}$ & $\begin{array}{l}125(48.3) \\
109(42.1) \\
25(9.6)\end{array}$ & $\begin{array}{l}80(47.1) \\
72(42.3) \\
18(10.6) \\
0.686\end{array}$ & $\begin{array}{l}27(48.2) \\
21(37.5) \\
8(14.3)\end{array}$ \\
\hline
\end{tabular}

Abbreviations: SNP, Single Nucleotide Polymorphism; ER, oestrogen receptor; PR, progesterone receptor; HER2, human epidermal growth factor receptor 2 .

${ }^{\mathrm{a}} p$-Value from Chi-square test. $p$-Values $<0.05$ in bold text.

breast cancer [18]. To date, studies investigating BC susceptibility focused on SNPs located within the prostate and breast cancer sub-region. Within this sub-region, two SNPs rs1562430 and rs13281615, were found associated with BC risk in women $[10,15]$. Of these two SNPs, located in the same linkage disequilibrium block, rs1562430 $\mathrm{T}$ allele (the common allele) showed a more significant association with increased FBC risk than the correlated rs13281615 $\mathrm{G}$ allele [15]. Recently, rs13281615 was examined for its association with BC risk also in men, but no significant association emerged $[22,23]$. In this study we investigated all the five $8 \mathrm{q} 24.21$ susceptibility sub-regions and genotyped 19 cancer-associated SNPs. Our results showed that two SNPs, rs1562430 and rs445114, both located in the $8 \mathrm{q} 24.21$ breast and prostate cancer sub-region, were associated with MBC risk, with rs1562430 showing a stronger and independent association. It is noteworthy that rs445114 was previously found as a prostate cancer specific susceptibility SNP [14]. Male breast and prostate cancers are hormonally driven diseases, and share biological similarities and risk factors [28]. Intriguingly, prostate cancer is the more frequent second malignancy that affects MBC patients [29]. Thus, the 8q24.21 breast and prostate cancer sub-region may have a pleiotropic effect, being involved in susceptibility of both MBC and prostate cancer. On the other hand, based on our results, a role of prostate-specific susceptibility sub-regions in MBC risk may be excluded. Studies of larger series of cases affected by both breast and prostate are needed to further investigate these hypotheses.

In this study, we also showed that other common BC susceptibility SNPs across the genome (rs1011970/ 9p21.3, rs614367/11q13.3 and rs1314913/14q24.1) were associated with MBC susceptibility in our population. These results are in agreement with and corroborate findings from a previous GWAS study on MBC from different populations [23].

The rs1011970/9p21.3 lies in a block that includes $C D K N 2 A$ and $C D K N 2 B$, genes that are frequently mutated or deleted in several human tumours. $C D K N 2 \mathrm{~A}$ germ-line mutations predispose to malignant melanoma and pancreatic cancer. Intriguingly, these two types of cancer are often found in families with MBC, particularly in families whose BC susceptibility is associated with $B R C A 2$ mutations [30].

The rs614367/11q13.3 lies in gene-desert region. Fine-scale mapping of this region has identified a candidate causal variant that is a regulatory element targeting cyclin D1 (CCNDI) gene and that may be associated with low CCND1 protein levels in tumours [31]. $C C N D 1$ somatic alterations, such as copy number gain, are very frequent in $\mathrm{MBC}$, and seem to be correlated with poor prognosis [32]. 
The rs1314913/14q24.1, located in intron 7 of $R A D 51 B$ gene, was previously identified as a specific MBC susceptibility allele by GWAS [23] and in our study showed the strongest association with increased MBC risk.

In the present study, we also tested possible associations between the identified MBC susceptibility SNPs and main clinical-pathologic characteristics. Differences in the distribution of rs614367/11q13.3 genotypes according to ER status and of rs1011970/9p21.3 according to HER2 status emerged.

The frequency of rs614367/11q13.3 risk genotype tended to be higher in ER+ cases. In agreement with our results, rs614367 was associated with $\mathrm{ER}+/ \mathrm{PR}+\mathrm{FBCs}$, consistently with the role of CCND1 as a mediator of oestrogen-induced cell proliferation [33].

In our MBC series rs1011970/9p21.3 risk genotype was associated with HER2+ disease. The association of rs1011970 with HER2 status was not previously evaluated in FBC [33].

ER/PR and HER2 status have been recognised as having a role as important prognostic factors and as predictive markers for the response to treatment with endocrine and trastuzumab therapy. Thus, identification of susceptibility SNPs with subtype-specific associations may improve our knowledge on the genetic predisposition to important $\mathrm{MBC}$ subtypes that may have prognostic and predictive value in the clinical setting.

There is growing evidence that low-penetrance alleles, associated with increased risk of $\mathrm{BC}$ in the general population, may also modify the risk of developing $\mathrm{BC}$ in BRCA1/2 mutation carriers [34]. In this study, we were able to compare $\mathrm{MBC}$ cases with $\mathrm{BRCA} 1 / 2$ mutations with a control series of unaffected male BRCA1/2 mutation carriers. By analyses restricted to $B R C A 1 / 2$ carriers, we provided the first evidence that rs1314913/14q24.1 was associated with MBC risk, suggesting that it may act as a modifier locus of the risk conferred by BRCA1/2 mutations in men. Further studies in larger populations are needed to validate our findings.

Although we had overall a large sample size compared to other MBC series thus far analysed, the power of the study may be modest in order to identify smaller risk effects. Moreover, information on tumour characteristics was not available for all cases, and these data had been predominantly abstracted from medical records, rather than being obtained through a standardised pathology review. Thus, some associations may be underestimated.

In conclusion, we showed for the first time that common low-penetrance BC susceptibility alleles within 8q24.21 region, and in particular, rs1562430, play a role in MBC susceptibility. Moreover, we validated three BC susceptibility SNPs, including the MBC-specific SNP rs1314913, in the Italian population and provided the first evidence that this SNP may act as a risk modifier locus in male BRCA1/2 carriers. Overall, our present findings add new data to the accumulating evidence that common low-penetrance susceptibility alleles play a relevant role in MBC susceptibility.

\section{Sources of support}

Study supported by AIRC (IG12780) to L.O. and FIRC (triennial fellowship "Mario e Valeria Rindi") to V.S.

\section{Conflict of interest statement}

None declared.

\section{Acknowledgments}

We acknowledge AIRC and FIRC for funding this study. The funders had no role in the design and conduct of the study; collection, management, analysis and interpretation of data; preparation, review, or approval of the manuscript, and decision to submit the manuscript for publication.

\section{Appendix A. Supplementary data}

Supplementary data associated with this article can be found, in the online version, at http://dx.doi.org/10. 1016/j.ejca.2015.07.020.

\section{References}

[1] Ottini L. Male breast cancer: a rare disease that might uncover underlying pathways of breast cancer. Nat Rev Cancer 2014;14(10):643.

[2] Korde LA, Zujewski JA, Kamin L, Giordano S, Domchek S, Anderson WF, et al. Multidisciplinary meeting on male breast cancer: summary and research recommendations. J Clin Oncol 2010;28:2114-22.

[3] Rizzolo P, Silvestri V, Tommasi S, Pinto R, Danza K, Falchetti $\mathrm{M}$, et al. Male breast cancer: genetics, epigenetics, and ethical aspects. Ann Oncol 2013;24(Suppl. 8):viii75-82.

[4] Antoniou AC, Easton DF. Models of genetic susceptibility to breast cancer. Oncogene 2006;25(43):5898-905.

[5] Jostins L, Barrett JC. Genetic risk prediction in complex disease. Hum Mol Genet 2011;20(R2):R182-8.

[6] Fanale D, Amodeo V, Corsini LR, Rizzo S, Bazan V, Russo A. Breast cancer genome-wide association studies: there is strength in numbers. Oncogene 2012;31(17):2121-8.

[7] Maxwell KN, Nathanson KL. Common breast cancer risk variants in the post-COGS era: a comprehensive review. Breast Cancer Res 2013;15(6):212.

[8] Haiman CA, Patterson N, Freedman ML, Myers SR, Pike MC, Waliszewska A, et al. Multiple regions within 8q24 independently affect risk for prostate cancer. Nat Genet 2007;39(5):638-44.

[9] Zanke BW, Greenwood CM, Rangrej J, Kustra R, Tenesa A, Farrington SM, et al. Genome-wide association scan identifies a colorectal cancer susceptibility locus on chromosome 8q24. Nat Genet 2007;39(8):989-94. 
[10] Easton DF, Pooley KA, Dunning AM, Pharoah PD, Thompson D, Ballinger DG, et al. Genome-wide association study identifies novel breast cancer susceptibility loci. Nature 2007;447(7148): 1087-93.

[11] Eeles RA, Kote-Jarai Z, Giles GG, Olama AA, Guy M, Jugurnauth SK, et al. Multiple newly identified loci associated with prostate cancer susceptibility. Nat Genet 2008;40(3):316-21.

[12] Tomlinson IP, Webb E, Carvajal-Carmona L, Broderick P, Howarth K, Pittman AM, et al. A genome-wide association study identifies colorectal cancer susceptibility loci on chromosomes 10p14 and 8q23.3. Nat Genet 2008;40(5):623-30.

[13] Kiemeney LA, Thorlacius S, Sulem P, Geller F, Aben KK, Stacey $\mathrm{SN}$, et al. Sequence variant on $8 \mathrm{q} 24$ confers susceptibility to urinary bladder cancer. Nat Genet 2008;40(11):1307-12.

[14] Gudmundsson J, Sulem P, Gudbjartsson DF, Blondal T, Gylfason A, Agnarsson BA, et al. Genome-wide association and replication studies identify four variants associated with prostate cancer susceptibility. Nat Genet 2009;41(10):1122-6.

[15] Turnbull C, Ahmed S, Morrison J, Pernet D, Renwick A, Maranian M, et al. Genome-wide association study identifies five new breast cancer susceptibility loci. Nat Genet 2010;42(6):504-7.

[16] Ghoussaini M, Song H, Koessler T, Al Olama AA, Kote-Jarai Z, Driver KE, et al. Multiple loci with different cancer specificities within the 8q24 gene desert. J Natl Cancer Inst 2008;100(13): 962-6.

[17] Wokołorczyk D, Lubiński J, Narod SA, Cybulski C. Genetic heterogeneity of $8 \mathrm{q} 24$ region in susceptibility to cancer. J Natl Cancer Inst 2009;101(4):278-9.

[18] Wasserman NF, Aneas I, Nobrega MA. An 8q24 gene desert variant associated with prostate cancer risk confers differential in vivo activity to a MYC enhancer. Genome Res 2010;20(9): $1191-7$.

[19] Huppi K, Pitt JJ, Wahlberg BM, Caplen NJ. The 8q24 gene desert: an oasis of non-coding transcriptional activity. Front Genet 2012;3:69.

[20] Meyer N, Kim SS, Penn LZ. The Oscar-worthy role of Myc in apoptosis. Semin Cancer Biol 2006;16:275-87.

[21] Sapkota Y. Germline DNA variations in breast cancer predisposition and prognosis: a systematic review of the literature. Cytogenet Genome Res 2014;144(2):77-91.

[22] Orr N, Cooke R, Jones M, Fletcher O, Dudbridge F, ChilcottBurns S, et al. Genetic variants at chromosomes $2 \mathrm{q} 35,5 \mathrm{p} 12$, 6q25.1,10q26.13, and 16q12.1 influence the risk of breast cancer in men. PLoS Genet 2011;7(9):e1002290.

[23] Orr N, Lemnrau A, Cooke R, Fletcher O, Tomczyk K, Jones M, et al. Genome-wide association study identifies a common variant in RAD51B associated with male breast cancer risk. Nat Genet 2012;44(11):1182-4.

[24] Ottini L, Silvestri V, Saieva C, Rizzolo P, Zanna I, Falchetti M, et al. Association of low-penetrance alleles with male breast cancer risk and clinicopathological characteristics: results from a multicenter study in Italy. Breast Cancer Res Treat 2013;138(3): $861-8$.

[25] Haiman CA, Chen GK, Vachon CM, Canzian F, Dunning A, Millikan RC, et al. A common variant at the TERT-CLPTM1L locus is associated with estrogen receptor-negative breast cancer. Nat Genet 2011;43(12):1210-4.

[26] Ghoussaini M, Fletcher O, Michailidou K, Turnbull C, Schmidt MK, Dicks E, et al. Genome-wide association analysis identifies three new breast cancer susceptibility loci. Nat Genet 2012;44(3):312-8.

[27] Ottini L, Silvestri V, Rizzolo P, Falchetti M, Zanna I, Saieva C et al. Clinical and pathologic characteristics of BRCA-positive and BRCA-negative male breast cancer patients: results from a collaborative multicenter study in Italy. Breast Cancer Res Treat 2012;134(1):411-8.

[28] Risbridger GP, Davis ID, Birrell SN, Tilley WD. Breast and prostate cancer: more similar than different. Nat Rev Cancer 2010;10(3):205-12.

[29] Hemminki K, Scelo G, Boffetta P, Mellemkjaer L, Tracey E, Andersen A, et al. Second primary malignancies in patients with male breast cancer. Br J Cancer 2005;92(7):1288-92.

[30] Moran A, O'Hara C, Khan S, Shack L, Woodward E, Maher ER, et al. Risk of cancer other than breast or ovarian in individuals with BRCA1 and BRCA2 mutations. Fam Cancer 2012;11(2): $235-42$.

[31] French JD, Ghoussaini M, Edwards SL, Meyer KB, Michailidou $\mathrm{K}$, Ahmed $\mathrm{S}$, et al. Functional variants at the $11 \mathrm{q} 13$ risk locus for breast cancer regulate cyclin D1 expression through long-range enhancers. Am J Hum Genet 2013;92(4):489-503.

[32] Kornegoor R, Moelans CB, Verschuur-Maes AH, Hogenes MC, de Bruin PC, Oudejans JJ, et al. Oncogene amplification in male breast cancer: analysis by multiplex ligation-dependent probe amplification. Breast Cancer Res Treat 2012;135(1):49-58.

[33] Lambrechts D, Truong T, Justenhoven C, Humphreys MK, Wang J, Hopper JL, et al. 11q13 is a susceptibility locus for hormone receptor positive breast cancer. Hum Mutat 2012;33(7): $1123-32$.

[34] Milne RL, Antoniou AC. Genetic modifiers of cancer risk for BRCA1 and BRCA2 mutation carriers. Ann Oncol 2011;22(Suppl 1):i11-7. 